\title{
Factors Influencing Adoption and Area under Conservation Agriculture: A Mixed Methods Approach
}

\author{
Progress H. Nyanga ${ }^{1}$ \\ ${ }^{1}$ Department of International Environment and Development Studies (Noragric), Norwegian University of Life \\ Sciences, Norway \\ Correspondence: Progress H Nyanga, Department of International Environment and Development Studies \\ (Noragric), Norwegian University of Life Sciences, Norway. Tel: 47-6496-5200. E-mail: pnyanga@yahoo.co.uk
}

Received: January 4, 2012 Accepted: January 28, 2012 Online Published: July 6, 2012

doi:10.5539/sar.v1n2p27 URL: http://dx.doi.org/10.5539/sar.v1n2p27

This study was conducted under Conservation Agriculture Programme in Zambia funded by the Norwegian Ministry of Foreign Affairs through the Royal Norwegian Embassy in Lusaka to the Zambia National Farmers Union's Conservation Farming Unit. The views expressed in this paper are not of the sponsors but the views of the author

\begin{abstract}
Adoption of conservation agriculture (CA) is quite low in most parts of Africa. However, Zambia has been quite successful in increasing adoption of CA among smallholder farmers. Few studies using both quantitative and qualitative approaches have been conducted in Zambia to determine factors influencing adoption of CA. This study uses mixed methods approach to document factors influencing adoption of CA among smallholder farmers under the Conservation Agriculture Project (CAP) in Zambia. From a random sample of 415 smallholder farmers, results showed that $71 \%$ had adopted CA. Quantitative analysis indicated that CA trainings, previous experience in minimum tillage, membership in farmer organisations, and ownership of CA tillage equipment significantly increased the likelihood of CA adoption. Number of CA trainings attended, farm size, number of rippers owned and use of herbicide had a significant positive influence on area under CA. Qualitative approaches showed that good rapport with farmers, trust, reciprocity and altruism, monitoring and evaluations, extension strategy, quality and extent of technical knowledge in CA within CFU, and artificial incentives positively influenced adoption of CA. Traditional leadership was reported to enhance adoption of CA in most cases. Prestige was reported to withhold some men from adopting CA basins. Women were very involved in CA basins while men were mostly involved in ADP ripping. Some worldviews of farmers had negative influence on adoption of CA. Donor support and collaboration with the Zambia National Farmers Union and private sector were other contextual factors for the high adoption of CA among sampled smallholder farmers. In the promotion of CA it is important to pay attention to both quantitative and qualitative factors influencing adoption. A mixed methods approach thus can lead to a better understanding of the adoption of CA than a single research strategy approach.
\end{abstract}

Keywords: Mixed research methods, innovation adoption, smallholder farmer, gender, conservation agriculture, Zambia

\section{Introduction}

Conservation agriculture (CA) is increasingly being promoted as one of the options for addressing food insecurity (FAO, 2011b). Adoption of CA in most parts of Africa is low with not more than one percent of cropped land on the continent under CA (Kassam, Friedrich, Shaxson, \& Pretty, 2009). CA is claimed to offer benefits of increased soil organic matter, improvements in water harvesting, reduction of the risk of crop failure, increased and stabilised yields, reduction in soil erosion, improvement in soil structure, reduced pests and diseases, reduced weed germination, and increased productivity (Derpsch, Friedrich, Kassam, \& Hongwen, 2010; Li et al., 2011; Marongwe et al., 2011). Despite these claimed benefits, area under CA is small and adoption rates in most parts of the world are small and adoption rates in most parts of the world are low though steadily increasing (Derpsch et al., 2010; Friedrich, Derpsch, \& Kassam, 2011; Kassam et al., 2009). At a global level, CA accounted for about $8 \%$ of arable and permanent cropped land; less than $1 \%$ in Africa and about $4 \%$ in Zambia during the 2009/2010 farming season (Friedrich et al., 2011). 
CA has widely been defined as an agricultural practice with three interrelated core principles: minimum mechanical soil disturbance, permanent organic soil cover and diversified crop species in rotation or associations including legumes (FAO, 2011b; Govaerts et al., 2009; Hobbs, Sayre, \& Gupta, 2008). CA agronomic practices are essential for soil and water conservation, building and maintaining healthier soils, sustainable optimal production and maintenance of a rich agro-biodiversity and also important as a response to climate change (Dumanski, Peiretti, Benetis, McGarry, \& Pieri, 2006; Twomlow \& Hove, 2006). CA is claimed to provide farmers with a means for optimising their yields and profits while maintaining a balance between agricultural, economic and environmental benefits on a sustainable basis (CFU, 2006; FAO, 2006). These potential benefits of CA have led to an increase in the promotion of CA by donors, international development agencies, regional political bodies, national governments, farmers unions and non-governmental organisations. Despite more than 30 years of promoting CA in Africa, the adoption of CA has experienced low rates (Derpsch et al., 2010) especially beyond CA project period (Giller, Witter, Corbeels, \& Tittonell, 2009).

Knowler and Bradshaw (2007) provide an extensive review of recent studies on adoption of CA. The review shows that quantitative methods were mostly used in the studies on adoption. While quantitative approaches are useful in showing scale, trends, patterns, tendencies and generating generalisations, they are limited in explaining the context under which various factors influence adoption of an innovation. Qualitative methods provide information on social dimensions and processes influencing the adoption of CA and additional information on how and why various factors influence adoption of an innovation. However, qualitative approaches are limited in showing scale, tendencies, trends, and in making generalisations. Mixed methods research is an approach to inquiry that combines or associated quantitative and qualitative strategies (Creswell, 2009:4). Mixed methods approach offers an opportunity to draw strengths from each research strategy in a single study (Johnson \& Onwuegbuzie, 2004). Few studies have been conducted in Zambia to determine factors influencing adoption of CA (Chomba, 2004; Kabamba \& Muimba-Kankolongo, 2009; Kabwe, 2010). These studies also show a domination of quantitative methods in explaining adoption of conservation agriculture. Carvalho and White (1997) point out that mixed methods provide a more comprehensive analysis of the research problem than a single research strategy.

It is against the above background that this study documents factors influencing adoption of conservation agriculture in Zambia among smallholder farmers under the Conservation Agriculture Project (CAP) using mixed methods approach. The findings of this study are important in identifying factors that can further increase adoption of $\mathrm{CA}$ in addition to contributing to scientific knowledge. Hence, these findings could be useful to policy makers, donors and agencies promoting and implementing CA projects.

\subsection{CA and CAP in Zambia}

To the above definition of CA the Conservation Farming Unit (CFU) includes planting of Faidherbia albida for soil fertility improvement (CFU, 2011:78). There are two main variants of CA in Zambia: hand hoe based CA (Figure 1) and animal draft powered (ADP) CA (ripping) (Figure 2). A third variant, tractor based CA is not common (Figure 3).

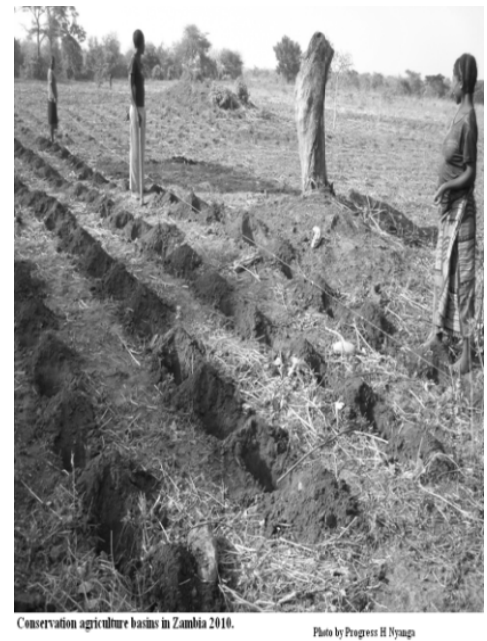

Figure 1. Conservation agriculture basins in Zambia in 2010

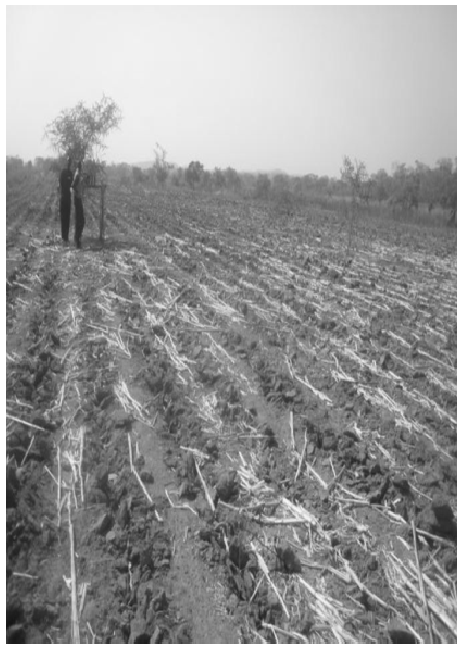

Figure 2. Animal draft powered CA (ripping) in Zambia in 2010

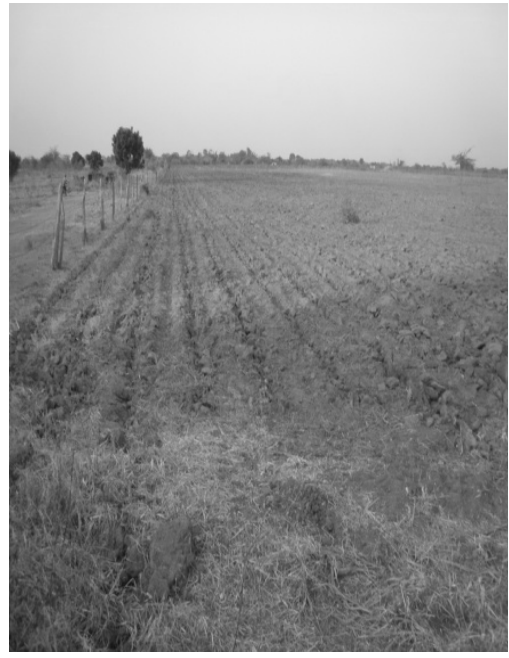

Figure 3. Tractor based CA in Zambia in 2010 
Hand hoe based CA involves digging of CA planting basins (CA basins) spaced at 0.7 meters along the rows and 0.9 meters between rows using a Chaka hoe (CFU, 2009b). Crop residues and other vegetative matter are supposed to be retained on the surface as permanent organic soil cover in the area between the basins. The recommended dimensions of a basin are 0.2 meters in depth, 0.3 meters in length and the same width as that of the blade of the Chaka hoe (CFU, 2009b). A Chaka hoe has an elongated thick strong blade and a long handle as compared to a traditional hand hoe. These features of a Chaka hoe account for its heaviness relative to a traditional ones. Hand hoe based conventional agriculture involves tilling of the whole field using a traditional hand hoe or making ridges resulting in maximum soil disturbance.

The animal draft powered CA (ADP ripping) uses a Magoye ripper instead of a conventional mould board plough. Instead of complete soil inversion in conventional agriculture with a plough, farmers practicing ADP ripping make at least 0.15-0.20 meters deep ripped furrows at 0.9 meters spacing in CA and retain the crop residues and other vegetative matter between ripped lines (CFU, 2009a). Minimum tillage restricts soil disturbance to precise a area where the crop is sown resulting in a minimum soil disturbance of around $10 \%$ of the area in both CA basins and ADP ripping (FAO, 2011a) .

Haggblade and Tembo (2003b) give the history of conservation farming (CF) in Zambia tracing its development and diffusion from the late 1980s and early 1990s. Since the mid 1990s, the Conservation Farming Unit (CFU) of the Zambia National Farmers Union (ZNFU), has championed the training of both institutions and individual farmers in CA in the country (FAO, 2011a). In a series of donor supported projects, the Conservation Agriculture Project (CAP) is a recent project implemented by CFU from 2007 to 2011 funded mainly by the Norwegian Ministry of Foreign Affairs through the Royal Norwegian Embassy in Zambia (CFU, 2006).

\subsection{Theoretical Perspectives}

There are various theoretical perspectives that inform studies on adoption of innovations. Rogers' innovation-diffusion theoretical perspective identifies information dissemination as a key factor in influencing adoption decision (Rogers, 2003). The adoption-decision process is seen as a linear sequence of stages starting by the knowledge stage in which a farmer gets information and knowledge about an innovation, followed by a persuasion phase in which a farmer forms an attitude towards the innovation (Rogers, 2003:161-163). After persuasion, stage follows decision stage in which a decision is made to adopt or not to adopt. Adoption is seen as the best course of action available (Rogers, 2003) and adopters are considered rational (Mwaseba, Kaarhus, Johnsen, Mvena, \& Mattee, 2006). Implementation is the fourth stage in which there is an overt behavioural change by using the new innovation. The implementation stage may involve adapting or reinventing the innovation to suit the local conditions. The final stage is the confirmation stage where farmers may either decide to continue if they are satisfied with the outcomes of implementation or abandon the innovation if not satisfied.

The economic constraints theoretical perspective (Aikens, Havens, \& Flinn, 1975 cited in Adesina \& Zinnah, 1993) postulates that technology adoption is influenced by economic factors and economic constraints due to asymmetric distribution of resources. Lack of ownership and access to capital constrain farmers from adopting new innovations. The adopter-perceptions theoretical perspective (Adesina \& Zinnah, 1993), a variant of the economic constraint theory, includes perceptions of farmers in explaining adoption. However, these schools of thoughts do not adequately address the role of social learning in adoption of innovations.

Social learning theoretical perspective (Bandura, 1977) postulates that people learn by observing the behaviour of others. Learning may or may not result in change in behaviour depending on the level of attention of the learner (cognitive capacity), ability to remember the observed behaviour (retention capacity), ability to replicate the observed behaviour (motor capacity) and ability to want to put into practice the observed behaviour (motivation level) (Bandura, 1977). Adoption of an innovation is seen as a social process in which learning of knew practices occurs both in formal and informal settings through sharing information, observation, imitation, or as a normative action (Bandura, 1969). Networks (Long, 1992), values and norms (Rogers, 2003:24-26), structures in society and human agency (Giddens, 1984) have an influence on the process of social learning and adoption of innovations.

\section{Methods}

The study areas were chosen because CAP was operating here. They were organised into four regions: Southern, Central, Western and Eastern for operational purposes of CAP. The districts Choma, Kalomo, Monze, Mazabuka and Sinazeze constitute the Southern region; Chibombo, Kapiri Mposhi, and Chongwe constitute the Central region; Western region has Mumbwa district while the Eastern region consists of Chipata, Katete and Petauke districts (Figure 4). 


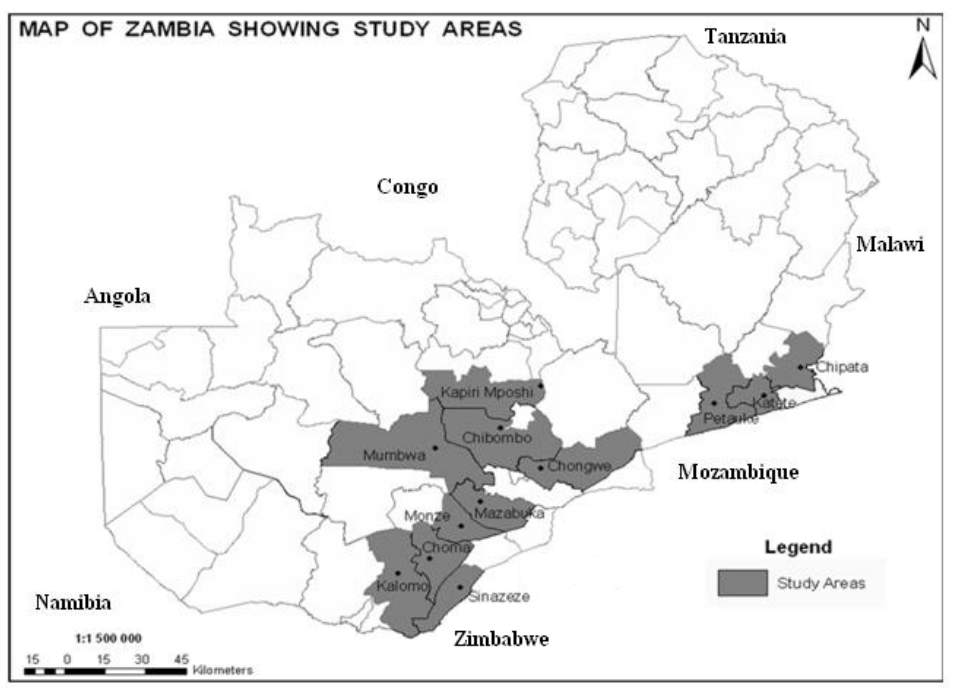

Figure 4. Study areas

CAP had targeted 120,000 smallholder farmers to adopt CA from 2007 to 2011. In this study, smallholder farmers are farmers farming less than 20 hectares (Haggblade \& Tembo, 2003a). CFU provided extension services to selected smallholder farmers in the study areas using a lead farmer extension model in an effort to increase the adoption of CA. Most of the farmers in the study areas practiced mixed farming with maize, sweet potatoes, cassava, mixed beans, cowpeas, cotton, sorghum, millet, sweet stalks, pumpkins, water melons and cucumbers as main crops and cattle, goats, pigs and poultry as major types of livestock. The agricultural system is mainly rain-fed and farmers seldom practice irrigation (Siegel \& Jeffrey, 2005).

\subsection{Data collection and Analysis}

Mixed methods were used in collection of data. Mixed methods approach offered an opportunity to draw from the strengths of both quantitative and qualitative research approaches (Johnson \& Onwuegbuzie, 2004). Quantitative data was collected using a questionnaire on 415 smallholder farmers that were randomly sampled from updated CAP registers of 120000 smallholder farmers.

Qualitative information used in this study is based on 14 focus group discussions: Four with women only, four with men only and six with both women and men. Key informants (30) were also interviewed. Key informants included CFU management, agricultural extension staff, village headmen, lead farmers, and leaders of local farmer organisations and women clubs. Purposive sampling was used in the selection of key informants and focus group discussants so as to have participants who are known to have opinions and experiences on the topics for discussion. Information was also collected through informal discussions with farmers and key informants. Review of literature such as extension manuals, monitoring and evaluation reports, were also used in data collection.

Qualitative analysis of information was a continuous process starting during data collection on identified major themes and ending with an in-depth description of the results. In other words exploratory thematic and content analysis (Johnson \& Onwuegbuzie, 2004) and content analysis was used for this study. Direct quotations of key expressions were also used but the names and places of respondents were not disclosed due to ethical reasons.

An area under minimum tillage was used as an indicator of adoption of CA because minimum tillage is the most founder mental difference from conventional agriculture. Crop rotation was already a common practice among farmers (about 90\%) among sampled farmers (Nyanga, Johnsen, \& Aune, 2011). Crop residue retention was a major challenge because fields soon after harvest were open for communal grazing thus making it hard to have permanent soil cover with organic matter. Hence, a household that had area under minimum tillage was considered as practicing CA in 2009/2010 farming season.

A number of school of thought influence the choice of variables in adoption studies. These include innovation and diffusion (Rogers, 2003); economic constraint (Aikens, 1975:cited in Adesina \& Zinnah, 1993)); adopter perception (Adesina \& Zinnah, 1993); actor oriented (Long, 1992; Mwaseba et al., 2006) and sustainable 
livelihoods (Chambers \& Conway, 1991; Mwaseba et al., 2006). These guided the selection of variables for the regression models to determine factors influencing adoption and the extent of area under CA. Descriptive statistics with means and percentages were used to summarise quantitative data. Differences between CA adopters and non adopters in explanatory variables were tested using t-test and associations were tested using chi-square test.

A binary logistic regression was used in CA adoption model to determine factors influencing adoption of CA. According to the diffusion of innovation theoretical perspective a farmer's response towards an innovation is binary, either adopts or rejects. Hence the model for CA adoption was specified as Logit $(\mathrm{P}(\mathrm{y}=1))=\log$ $(\mathrm{P} /(1-\mathrm{P}))=\alpha+\beta_{1} \mathrm{X}_{1}+\beta_{2} \mathrm{X}_{2}+\ldots+\beta_{\mathrm{K}} \mathrm{X}_{\mathrm{K}}$ where $\mathrm{Y}$ is a categorical response variable with $1=$ adopters and $0=$ otherwise; $\alpha$ is the intercept; $\beta_{1}, \beta_{2} \ldots . \beta_{\mathrm{k}}$ are coefficients of independent variables $\mathrm{X}_{1} \mathrm{X} 2 \ldots \mathrm{X}_{\mathrm{K}} ; \mathrm{P}$ is the probability of adopting CA and (1-P) is the probability that a farmer does not adopt CA. Since a farmers either had an area under CA (adopter) or no area under CA (non adopter) it was most appropriate to use a binary logistic regression model (Agresti, 2007) for the purposes of understanding factors explaining the likelihood of CA adoption. However, the logistic regression does not assess the extent or intensity of adoption. Hence, a general linear regression was used in explaining area under CA. This was important because it provides additional information in identifying factors influencing the extent of CA adoption in terms of area. This model was also suitable because it made it easy to investigate relationships between a continuous response variable (Area) and some explanatory variables some being continuous and others categorical (MINITAB, 2010). The area under $\mathrm{CA}$ is influenced by a set of variables, in the model for area under CA, specified as $\mathrm{Y}=\alpha+\beta 1 \mathrm{X} 1 \mathrm{i}+\beta 2 \mathrm{X} 2 \mathrm{i}+\ldots+$ $\beta \mathrm{kXki}+\varepsilon \mathrm{i}$ where $\mathrm{Y}$ is a continuous response variable (area in hectares); $\alpha$ is the intercept; $\beta 1, \beta 2 \ldots . \beta \mathrm{k}$ are coefficients of independent variables X1 X2 .. Xk; $\varepsilon i=$ error term and $i=i$ ith observation in the sample.

A concurrent design was used in combining qualitative and quantitative methods for the purposes of triangulation and complementarities. Nweing (2011) defines a concurrent design in mixed methods as use of quantitative and qualitative approaches in parallel either for the purposes of triangulation or complementation to address different aspects of the overall research question. The results from quantitative and qualitative approaches were combined as suggested by Carvalho \& White (1997) in order to provide a comprehensive analysis.

\section{Result and Discussion: Factors influencing the Adoption of CA}

Most of the adoption of CA in Africa is supported by donor community and international development agencies (Giller et al., 2009). Donor support and collaboration with the Zambia National Farmers Union and private sector were among contextual factors behind the high adoption levels CA observed among sampled households. The section below presents descriptive statistics of explanatory variables used in regression models.

\subsection{Explanatory Factors for Adoption}

Results showed that $71 \%$ (296) of smallholder farmers in the sample were practicing CA while $29 \%$ (119) were not. The average area under CA was 0.5 hectares for the whole sample and 0.8 hectares among CA adopters. CA accounted for $26 \%$ of the total cropped area ( $876.1 \mathrm{ha}$ ) in the sample in the 2009/2010 farming season. There were significant differences between CA adopters and non adopters in in attendance of CA trainings, membership in agricultural related organisations, access to credit, distance to the nearest market, ownership of animal draft power (ADP) and ownership of CA tillage equipment (chaka hoe and ripper) (Table 1). There was also significant association between pre-CAP experience with minimum tillage and farmer classification (CA adopter or non-CA adopter). Results and discussion of various factors influencing the adoption of CA are given in the following sections.

\subsection{Trainings and Rapport}

The CA adoption model showed that training in CA significantly increased the likelihood of adoption of CA (Table 2). CA trainings also had a significant positive influence on the area under CA as indicated by the model for the area under CA (Table 2). This is because CA trainings were the most important source of information on CA practices. Triangulation with perceptions of farmers indicated that $90 \%$ of farmers perceived that CFU trainings in CA were the most important source of information on CA practices. These results are consisted with innovation diffusion theory (Rogers, 2003) that postulates that information access is central in the process of innovation adoption. 
Table 1. Descriptive statistics for explanatory variables used in the regression models

\begin{tabular}{|c|c|c|c|c|}
\hline Variables & Variable description & CA-adopters & Non-adopters & P-value \\
\hline \multirow[t]{3}{*}{ Location } & $1=$ Drought prone region $0=$ Otherwise $(\%)$ & & & \multirow[t]{3}{*}{0.473} \\
\hline & Drought prone region (Southern region) $(n=105)(\%)$ & 68.6 & 31.4 & \\
\hline & $\begin{array}{l}\text { Non-drought prone regions (Central, western and } \\
\text { Eastern regions) }(\mathrm{n}=310)(\%)\end{array}$ & 72.3 & 27.7 & \\
\hline Type of & Sex of the head of household (\%) & & & \multirow{3}{*}{0.808} \\
\hline \multirow[t]{2}{*}{ household } & Female $(n=69)(\%)$ & 72.5 & 27.5 & \\
\hline & Male $(n=345)(\%)$ & 71.0 & 29.0 & \\
\hline Labour & Number of persons working per hectare ${ }^{a}$ & $5.1(0.91)$ & $3.3(0.27)$ & 0.060 \\
\hline Age & Number of years for the head of household ${ }^{a}$ & $44.5(0.85)$ & $47.2(1.4)$ & 0.098 \\
\hline Education & Years of formal schooling by household head ${ }^{\mathrm{a}}$ & $6.2(0.18)$ & $6.6(0.29)$ & 0.270 \\
\hline Farm size & Total area tilled in $2009 / 2010$ (hectares) $^{\mathrm{a}}$ & $2.0(0.12)$ & $2.1(0.26)$ & 0.719 \\
\hline \multirow[t]{3}{*}{ Herbicides } & Use of herbicide in 2009/2010 season (\%) & & & \multirow[t]{3}{*}{0.569} \\
\hline & Yes $(n=29)(\%)$ & 72.4 & 27.6 & \\
\hline & No $(n=339)(\%)$ & 67.3 & 32.7 & \\
\hline CA training & Number of trainings in CA attended last 12 months ${ }^{\mathrm{a}}$ & $3.0(0.19)$ & $1.6(0.17)$ & 0.000 \\
\hline Pre-CAP MT & Practised minimum tillage before CAP (\%) & & & \multirow[t]{3}{*}{0.000} \\
\hline \multirow[t]{2}{*}{ experience } & Yes $(n=187)(\%)$ & 82.3 & 17.7 & \\
\hline & No $(n=220)(\%)$ & 61.8 & 38.2 & \\
\hline Membership & $\begin{array}{l}\text { Number of agricultural organisations in which } \\
\text { household members belonged }^{\text {a }}\end{array}$ & $1.7(0.06)$ & $1.4(0.08)$ & 0.002 \\
\hline FISP & $\begin{array}{l}\text { Frequency accessed government subsidized } \\
\text { inputs beginning of CAP }\end{array}$ & $0.9(0.07)$ & $0.8(0.09)$ & 0.318 \\
\hline Credit & $\begin{array}{l}\text { Number of years that a household accessed } \\
\text { agricultural credit since beginning of CAP }\end{array}$ & $1.3(0.07)$ & $1.6(0.11)$ & 0.045 \\
\hline Distance & Time taken to the nearest market place (hours) ${ }^{\mathrm{a}}$ & $1.4(0.16)$ & $1.0(0.11)$ & 0.048 \\
\hline ADP & Number of trained animal draft power ${ }^{\mathrm{a}}$ & $1.5(0.14)$ & $2.3(0.35)$ & 0.041 \\
\hline Chaka hoe & Number of Chaka hoes owned by a household & $0.7(0.07)$ & $0.3(0.07)$ & 0.000 \\
\hline Rippers & Number of rippers owned by a household ${ }^{\mathrm{a}}$ & $0.2(0.03)$ & $0.1(0.03)$ & 0.004 \\
\hline TLÜ & Total livestock units ${ }^{\mathrm{b}}$ per capita $^{\mathrm{a}}$ & $0.4(0.04)$ & $0.5(0.07)$ & 0.271 \\
\hline Income & Annual cash income in million kwacha per capita ${ }^{c}$ & $0.7(0.05)$ & $0.9(0.14)$ & 0.168 \\
\hline
\end{tabular}

${ }^{a}$ The values show the means and the corresponding standard errors of means are presented in brackets

${ }^{\mathrm{b}}$ livestock unit is an animal unit that represents an animal of $250 \mathrm{~kg}$ live weight used to aggregate different types of livestock weighted as cattle $=0.5$, goat and sheep $=0.1$;pigs $=0.2$ and poultry $=0.02$ (Kalinda et al., 2008)

${ }^{\mathrm{c}} 1$ US Dollar $=4850$ Zambian Kwacha

Table 2. Regression estimates for factors explaining adopting CA and area under CA

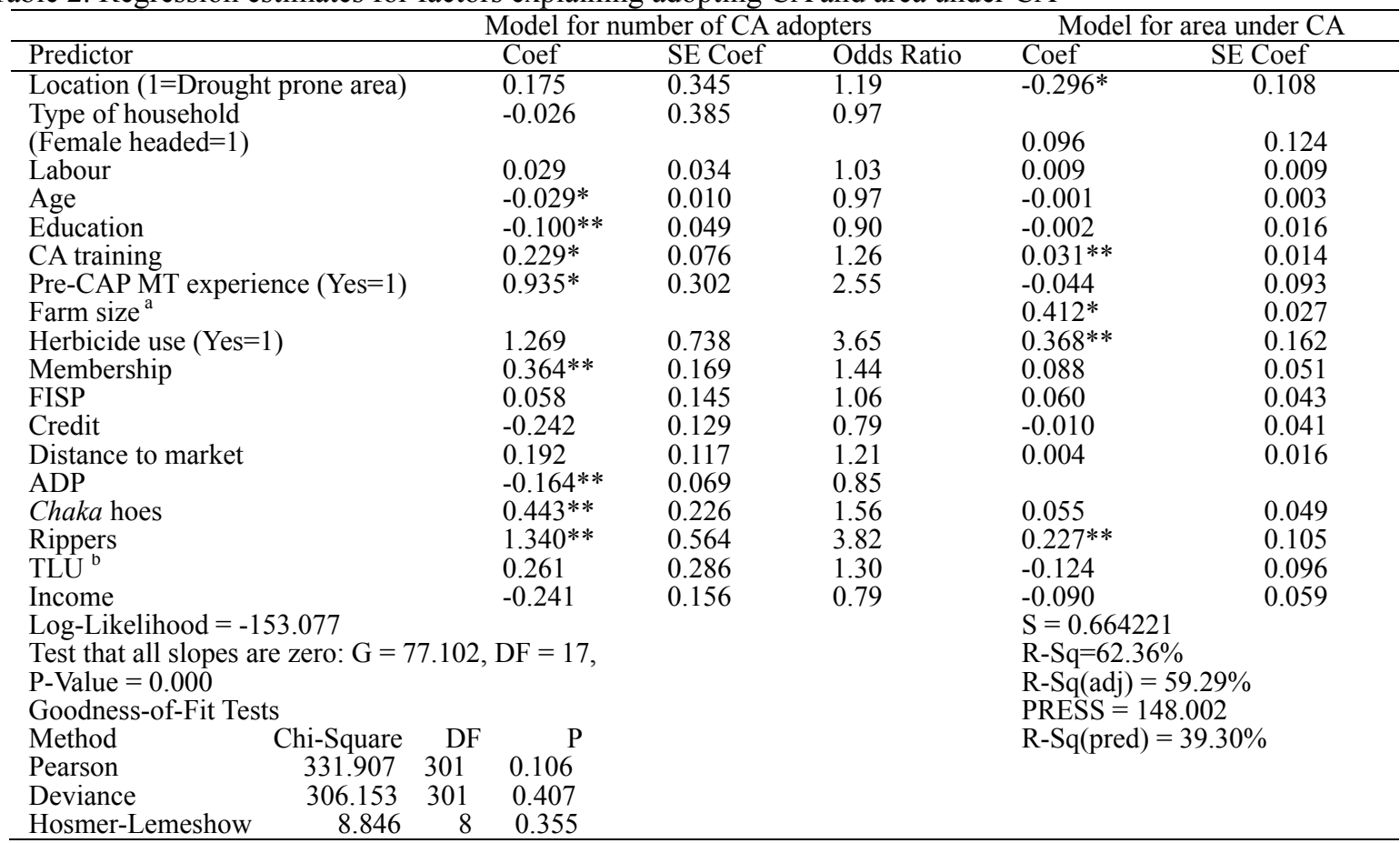

${ }^{a}$ Variable Farm size was dropped from the CA adoption model because of lack of dependence to the binary response variable (Odds ratio $=1.00$ and correlation coefficient 0.000 ).

${ }^{\mathrm{b}}$ ADP was dropped from the extent of adoption model because of co-linearity

*Significant at $0.01 ; * *$ Significant at 0.05 
Qualitative analysis indicated that good rapport was an important factor influencing CA adoption. Respondents reported that having a good trainer, agricultural extension staff and/or lead farmer, was important for adoption of CA. Farmers often expressed this view in statements such as "when you have a good leader (lead farmer or agricultural extension officer) most people attend the trainings and do what they are taught." Probing into what characterised a good leader revealed attributes such as being able to explain the contents of CA training materials in an easily understandable way, answering questions from farmers, having successful demonstrations, being approachable and showing concern and respect towards farmers. Although these attributes are subjective, the findings show that effective communication and good rapport between the extension system and farmers are important in enhancing the uptake of CA. Vanclay (2011) points out that good rapport and providing farmers with practical, useful answers that assist them in their day-to-day operations is important in enhancing adoption of new innovations. Adoption of CA is also influenced by an interaction of farmers' worldviews (previous farming experience, knowledge and objectives) and current efforts of CA promotion.

\subsection{Experience and Worldviews of farmers}

A regression model for CA adoption indicated that previous experiences with minimum tillage (pre-CAP MT experience) significantly increased the likelihood of CA adoption (Table 2). Farmers who had practised minimum tillage before CAP could easily relate to CA as an alternative farming system much more than those who were introduced to CA for the first time. Haggblade and Tembo (2003b) noted that the history of projects promoting CA in Zambia dates as back as the mid 1980s. Lessons learnt from previous projects could have made some farmers who participated in those projects to be in a better position to adopt CA in the current CAP than farmers who did not participate in any CA projects before. However, it has been noted that adoption rates of CA in Zambia often decrease substantially after projects end (Haggblade \& Tembo, 2003b). This study indicates that participation in previous projects increased the likelihood for a farmer to adopt CA in future.

However, not all experiences by a farmer enhanced adoption of CA as indicated by a significant negative coefficient for age in the regression model for CA adoption (Table 2). Results showed that it was less likely for an older farmer to adopt CA than a relatively younger one. This is mostly because of the long tradition of farming using conventional methods that had become part of what constitutes good farming practice from farmers' perspectives. An old farmer in her 70s explained that a good field is supposed to be "clean and cleared of crop residues..." a view contrary to the CA principle of permanent soil cover. Not all CA practices fall within the domain of good agronomic practices from some farmer's perspective. The view that conventional agriculture was the accepted way of farming was shared among respondents. This was noted through statements such as "conventional agriculture is how farming has been done even by our fore fathers; from childhood this (conventional agriculture) is how we have been farming; ploughing is how farming should be done; you cannot get rich through CA but through ploughing..." The long history of ploughing explains the negative significant effect on area under CA (Table 2) of the Southern region compared to other regions. This is because the Southern region is mostly inhabited by the Batonga (Tonga speaking people) who have a known long history of cattle rearing and using ploughs. These results are quite consistent with the adopter perception theoretical perspective that posits that perceptions and the history of potential adopters also influence the adoption process of an innovation (Adesina \& Zinnah, 1993).

Some of the farmers' reasoning and experiences were conflictive to CA practices. Some farmers explained that they were not adopting CA because CA prevented burning. Farmers argued that burning was a source of plant nutrients and a means of controlling weeds, pests and diseases. Use of animals (cattle) for dry season land preparation when the soils are hard was considered a sign of hostility in some communities. Farmers further argued that during the dry season, there is little pasture and the use of oxen to till hard and dry soils made the animals more susceptible to diseases than when soils are wet and soft, and pastures are plenty. Hence, the CA practice of dry season land preparation is not accepted among some farmers owning cattle. Use of herbicides to destroy weeds as soon as they emerged was not an ecologically good practice from some farmers' point of view. This is because some farmers had an understanding that weeds were essential for soil fertility when they decomposed. Hence, such farmers argued for the use of mechanical means to control weeds, a practice that is not consistent with the principle of minimum tillage and is not encouraged within CAP. Others argued that use of herbicides was good and soil fertility could still be improved by using Faidherbia albida though it would require longer time before realising significant results. An implication of such conflictive knowledge systems has led some farmers to weed CA plots using a cultivator, a practice not in line with CA principle of minimum soil disturbance. Such practices are consistent with the concept of innovation adaptation expressed as reinvention (Rogers, 2003) in the innovation-diffusion theory. Reinvention or adaptation of innovation is an essential process for making the innovation suitable for the local context. 


\subsection{Equipment and Prestige}

The CA adoption regression model showed that ownership of a chaka hoe increased the likelihood of adoption of CA significantly and so did ownership of a ripper (Table 2). This is because these implements are used for minimum tillage in CA among sampled farmers. The model for area under CA indicated that a ripper also had a positive and significant influence on area under CA. This is because of the labour saving effect of a ripper. Farmers often expressed the labour saving effect of a ripper through statements as "a ripper is very fast...; you can plant a large area within a short time with a ripper..." A chaka hoe had no significant effect on area under CA among CA adopters most likely because of lack of labour saving effect. Most farmers complained about the hoe being heavy and the task of digging basins was labour demanding thus limiting CA basins to a relatively small area. The survey confirmed that among those engaged in CA basins (256) the average area was significantly (p-value $<0.001)$ smaller $(0.5 \mathrm{ha})$ than average area $(1.2 \mathrm{ha})$ under ripping among those engaged (79). Other studies have shown that the use of the chaka hoe increased labour compared to the traditional hoe in conventional agriculture (Haggblade \& Tembo, 2003b). As argued by the economic constraint theoretical perspective, the asymmetric distribution of resources, CA equipment in this regard, influences adoption of new innovations (CA).

In relation to ownership of $\mathrm{CA}$ implements, social prestige was also influencing $\mathrm{CA}$ adoption. Focus group discussants and key informants explained that some men were reluctant to adopt CA basins because of prestige. Cases where men preferred to wait to hire a plough to digging of CA basins were reported in discussions. Farmers explained that a man's prestige often increased with increase in the number of hectares he was able to plant and later his crop production. This was mostly associated with conventional agriculture (use of a plough and cultivator) than with CA (using a ripper). Though most farmers acknowledged that harvest per unit area was higher in CA basins than in other tillage methods, prestige was more important to some men than the productivity benefits of CA. This shows that qualitative and non-economic factors are also critical in adoption of CA. In this regard some farmers are able to decide and act as postulated by the human agency theoretical perspective (Giddens, 1984; Long, 1992) not for an economic reason but a non-economic reason (prestige). Nonetheless, ADP ripping provides an opportunity for most men not only to increase productivity but also to secure their prestige of having large areas under cultivation. However, there is a challenge of increasing availability of CA equipment for smallholder farmers.

\subsection{Gender}

In the focus group discussions, farmers often pointed out that the practice of basins was done more by women than by men. Likewise, CA by ripping was done more by men than women. This is because hand hoeing was mostly in the domains of women than men. Similarly, use of animal draft power and thus ADP ripping was more in the domain of men than women. Similar results have been reported other studies (CFU, 2011). These results are in line with the structure agency theoretical perspective (Giddens, 1984) in which social structures like gender tend to influence human actions. Regression models showed no significant effect of the sex of the head of household on the adoption (Table 2). This could be because the use of the models does not adequately address the intra household relations between men and women when using sex of the head of household as an indicator.

\subsection{Equity Dimension of CA Innovation and Wealth}

Adoption of $\mathrm{CA}$ in the sample was also enhanced by the equity attributes of CA innovations. Having three variants of CA (Figure 1, Figure 2 and Figure 3) that catered for different categories of smallholder farmers also contributed to an increase in adoption. This is because multiple variants of CA provide an opportunity for a wide range of farmers with different socio-economic capacities to practice CA. Farming households that could not afford ADP ripping due to economic constraints had an opportunity to practice CA using basins. This could have been the case for most women farmers because women farmers often lack access and control to resources (McGowan, 2011). Farmers often expressed this equity dimension in phrases such as: "Even a poor person can practice CA using basins; the advantage of CA is that you don't have to depend on animals; it is cheaper to hire a ripper than a plough." Given the heterogeneity of farmers, promoting multiple variants of CA, hand hoe based $\mathrm{CA}$, ADP based CA and tractor based CA, can further increase the adoption. Although equity dimension can enhance the adoption of CA, this does not suggest that CA is wealth neutral.

Most indicators of wealth, ADP, level of education, access to credit and income had negative coefficients indicating that these variables reduced the likelihood of adopting CA by a farmer (Table 2). Ownership of cattle is one of the most distinguishing variables between resource poor and resource rich smallholder farmers. The negative significant coefficient of ADP ownership (Table 2) in the adoption model shows that the most resource rich farmers are less likely to adopt CA. Focus group discussants also pointed out that some farmers, especially 
those who were perceived to be rich by the community, did not see any need for adoption of CA. One of the relatively resource rich farmers aged 68, a retired civil servant, argued that he did not see any need to change from conventional agriculture to CA because he was quite comfortable with his levels of production and claimed that he was even doing better with conventional agriculture than farmers who were using $\mathrm{CA}$ in the same community.

However, farm size and use of herbicides as indicators of wealth were significant in increasing area under CA among CA adopters as shown in the model for area under CA. These results firstly show that relatively rich farmers are less likely to adopt CA but they have more capacity to increase area under CA than the resource poor farmers. This could mostly be because the relatively rich farmers are comfortable with their levels of production and livelihoods and simply do not see any need for allocating their resources towards CA. However, once they get convinced to adopt CA, the relatively rich farmers have resources to overcome the bottlenecks of labour associated with relatively large areas under CA. Secondly, certain factors that are not significant in influencing adoption of CA may become significant in influencing the up-scaling or increasing the area under CA. These findings are quite consistent with Rogers' innovation diffusion theoretical perspective that point out that adoption of innovation is a multi-staged process (Rogers, 2003). Each stage of the adoption process may be influenced by different factors. However, there is a need to investigate further exactly what components and levels of wealth could be influencing the up-scaling of CA at the household level.

\subsection{Institutional Aspects}

Membership in agricultural organisations had a significant positive influence on adoption of CA (Table 2). This is because farmers get various kinds of support such as legume seeds and CA trainings from agricultural organisations and non governmental organizations (NGOs) that they belong to. Other studies have also shown a positive relationship between adoption of conservation practices and membership in farmer organisations (Curtis \& De Lacy, 1996; Sobel, Curtis, \& Lockie, 2001).

However, other institutional aspects such as access to credit had a negative coefficient as indicated in the CA adoption model (Table 2). This indicates that access to credit reduced the likelihood of CA adoption. This is quite consistent with the earlier reasoning that relatively rich farmers who often have better access to credit are less likely to adopt CA. This could be because resource rich farmers have more livelihood options than the resource poor ones. Focus group discussants also pointed out that some farmers, especially those who were perceived to be rich by the community, did not see any need for adopting CA. A view that CA is for poor households was also reported by some farmers.

Qualitative methods further showed that the recruitment of village headmen as lead farmers and incorporating chiefs in the promotion of CA increased adoption of CA. Agricultural extension staff reported that some field demonstrations were conducted on farms of chiefs and headmen. The key informants explained that such trainings were often very well attended because chiefs and village headmen commanded some authority among their subjects. It was observed that, a number of lead farmers occupied some leadership positions like village headman, chair person for some local organisation, and church leader. Some of the agricultural extension staff also explained that some farmers adopted CA because they saw a chief or village headman or lead farmer practising CA successfully. A few cases where local leadership was less supportive towards CA were also observed. In one of these areas, lead farmers confessed that it was quite difficult to mobilise farmers for CA trainings because most of the farmers seemed to follow the opinion of their local significant persons. These results show that adoption of new innovation takes place in a social context as farmers learn by observing what others were doing. This is consistent with the social learning theory (Bandura, 1977) postulating that people also learn from each other both in formal and informal ways through observation and influence of significant persons in society. Key informants further reported that certain practices essential for CA such as not burning of crop residues had been enhanced through by-laws in some communities. This was done more for the purposes of securing feed for livestock than permanent soil covering purposes of CA as explained by a village headman. As such, communal grazing is still a common practice. These results suggest that crop residue retention may not be the best way of crop residue management from a broad livelihood perspective for farmers.

\subsection{Labour Sharing Arrangements, Reciprocity and Altruism}

Labour sharing arrangements between and among farmers was reported by focus group discussants to have a positive effect on adoption of CA. This is because such arrangements reduced the labour requirement for individual farmers on their respective plots. Key informants explained that labour sharing mechanisms involved, a group of farmers working in sequence from one field to the other for respective members. A day was often allocated to each member. Cases of labour sharing were noted mostly among farmer groups led by women. This 
was because women faced more challenges than men as reported by focus group discussants. These challenges included caring for children and being more responsible than men for what the family would eat each day. Additionally, altruistic behaviour also contributed towards adoption of CA. Some farmers had area under CA because a family member or friend either had given them some CA implement or dug basins or ripped for them. A case of altruistic behaviour was reported where a relative (lead farmer) had given his ripper and oxen to other farmers to use free of charge. His children were also reported to be ripping for some resource poor households. The lead farmer explained that: "I have been trained as a service provider by CFU to hire out services as ripping in my community. But some of my people do not have money to pay for ripping services and most of them have not experienced the goodness of CA. So I provide ripping services for free and some of the inputs from my remunerations as a farmer coordinator I also give to my members..." This was also confirmed by a neighbouring widow who had some area under ripping yet she reported no expenditure on labour and had no necessary implements. Triangulation with the questionnaire showed that the widow had no animal draft power and no ripper but had an area under ripping in the 2009/2010 farming season. These results show that norms of reciprocity, collectivism and corporation, and altruism, have a positive influence on the adoption of CA by overcoming the labour bottlenecks faced by individual households.

\subsection{Agricultural Extension Staff, Monitoring and Evaluation}

A dedicated and hard working agricultural extension staff had a positive influenced on adoption of CA. Agricultural extension staff explained that in order to secure their employment they had to meet specific targets set by CAP administration each year. Field officers and lead farmers further elaborated that such conditions forced agricultural extension staffs and lead farmers to work very hard in conducting trainings. Key informants further indicated that extension staff in CFU was specially trained in CA by experts in agronomic practices of CA within CFU. It is not surprising that most farmers (90\%) felt that CFU extension system was the most important source of information on CA. Monitoring and evaluation of CAP that were done by universities and private consultants contributed to enhancing of $\mathrm{CA}$ adoption. Feedback from monitoring and evaluations led to changes in strategies such as an increased focus on food legumes in crop rotation as opposed to using legumes such as velvet beans (CFU, 2011). Monitoring and evaluation reports indicated that there was an increase in crop rotation using legumes from $73 \%$ to $81 \%$ of farmers and the increase was attributed to an increased focus on food legumes (CFU, 2011; Nyanga et al., 2011). A high degree of knowledge in CA in an organisation, quality of extension services and feedback from farmers can enhance the adoption of CA.

However, having an effective extension system had unintended effects on adoption of CA. Key informants explained that some farmers were discouraged by the frequent change of agricultural extension staff. This was mainly because CFU's agricultural extension staff easily got jobs in other NGO because of their known competence. Cases were reported where farmers had become discouraged in attending CA training because the successor field officer was not as good as the predecessor. This could have had negative effect on CA adoption. Bandura (1969) points out that motivation as the ability to want to act is important in the learning process. Respondents often argued that having a good field officer and/or lead farmer usually made people follow what they were taught. Examination of lists of agricultural extension staff indicated that between $20 \%$ and $40 \%$ of areas under CAP changed agricultural extension staff each year. These changes have either positive or negative effects on CA adoption depending on whether the new extension officer meets the expectations of farmers. Although a result based management strategy is essential in getting an effective extension system, the same can lead to some unintended negative effects such as discouragement and loss of trust.

\subsection{Trust and Lack of Continuity in CA Projects}

Abandonment of certain areas by CAP contributed to a loss of trust among smallholder farmers in some areas. Certain areas were abandoned by CAP without farmers being informed. Discussions with CAP staff confirmed the withdrawal of CAP in those areas. Reasons for reported abandonment included lack of quick positive results, increased logistics on part of CAP, avoiding duplication of effort as other promoters had targeted same areas. Key informants explained that most farmers had stopped because of CAP's withdrawal and subsequent projects have also stopped. Some of the farming communities have experienced at least two to three different projects promoting CA starting and ending within a period of four years. One farmer complained that "...it seems they (CA promoters) are not serious; they come for a short time, give us some few material things (artificial incentives), make us rip and dig basins then they disappear.. At least we used to learn from CFU but it (CFU) has also disappeared...how do you expect us to continue with CA with such kind of interventions..? The lack of stability in CA projects could have contributed to the loss of trust in CA interventions among farmers in some areas. 
Additionally, some farmers reported a loss of trust in CAP because what had been promised when they registered under the project had not been fulfilled. Farmers claimed that they were promised free maize seed and fertiliser. Some informal discussions with key informants revealed that some false promises were made in order to meet the targeted number of adopters set by the project management and for the agricultural extension staff to secure their jobs. Others also argued that farmers were used to being given artificial incentives for practicing CA. Cases of farmers stopping CA after not getting the promised incentives were also reported. In one focus group discussion, most farmers threatened to stop CA if the promises made at the beginning of CAP were not going to be fulfilled.

Farmers were also questioning the credibility of some extension messages and practices. Some farmers reported that they were taught that herbicides would not disturb their crop rotation. However, focus group discussions revealed cases where legumes failed to germinate where herbicides had been sprayed the previous season. Others messages that some farmers cited to have contradicted their experience included reduction in weeds in CA and reduction in labour for digging basins. Some farmers argued that weeds were not reducing and labour demand increased not only due to increased weed pressure but also due to backfilling of basins to prevent water logging whenever there were excessive rainfalls. CA promoters often hide the potential challenges of CA from farmers. These results show that honest communication and securing the trust of the farmers are important in enhancing CA adoption. Vanclay (2011:62) has shown that winning the trust of farmers in development interventions and extension is essential for adoption of new technologies.

\subsection{Role of Incentives: Baits or Empowerment Packages?}

During interviews, farmers almost always asked what free items (artificial incentives) they would be given by the project for adopting CA. Others cited various kinds of artificial incentives such as free maize seed, fertiliser and food, which they got in previous CA projects. One key informant stated that "...there cannot be any meaningful adoption of CA in Zambia without giving farmers something (artificial incentive) no matter how little it is..." Some of the artificial incentives that farmers under CAP were given included free cassava cuttings (stems), legume seeds and sweet potato vines. These results show that artificial incentives are still a common feature in CA projects. However, once the project ends farmers may stop practising CA because they no longer get the artificial incentives. This could account for the observed increase in adoption rates during project periods and subsequent high rates of disadoption when projects end, observed by Haggblade and Tembo (2003a).

On the other hand, artificial incentives can effectively reduce farmers' risks associated with a new innovation. Artificial incentives also give farmers additional resources that can enable them to progress in CA. For artificial incentives to work as an empowerment package for the continued practice of CA beyond project period, NGOs and other international development agencies must change their focus from using incentives as baits. Instead, farmers must be given information that withholds them from perceiving incentives as the reason for adopting CA. Social welfare programmes have also contributed to the confusions in the use of incentives. Some farmers recalled being given food aid and inputs (poverty reduction starter packs) that were coupled with the requirement of adopting CA. This could have reinforced the perception among farmers that CA is a means to get various kinds of free resources rather than implementing it as an alternative farming system. These results suggest that the problem is not incentives in themselves but how and why incentives are used by various actors interacting with smallholder farmers. There is a need to focus beyond artificial incentives in development programmes and projects promoting CA so that farmers can continue practising CA after projects come to an end.

\section{Conclusion and Considerations}

This study has shown that both quantitative and qualitative factors influence the adoption of CA. Quantitative analysis indicated that CA trainings, previous experience with minimum tillage, membership in farmer organisations, and ownership of CA tillage equipment increased the likelihood of CA adoption significantly. Quantitative approaches further indicated that increase in number of CA trainings attended, farm size and number of rippers owned and use of herbicides had a positive significant influence on area under CA. Qualitative approaches showed that good rapport with farmers, trust, reciprocity and altruism, monitoring and evaluations, extension strategy, quality and extent of technical knowledge in CA within CFU, and artificial incentives positively influenced the adoption of CA. Traditional leadership was reported to enhance adoption of CA in most cases. Prestige was reported to withhold some men from adopting CA basins. Women were mostly involved in CA basins while men were mostly involved in ADP ripping. Some worldviews of farmers had negative influence on adoption of CA. Donor support and collaboration with the Zambia National Farmers Union and the private sector were other contextual factors for the high adoption of CA among sampled smallholder farmers.

The study raises the following considerations; attendance in CA trainings should be further encouraged; there is 
need to improve access to appropriate CA tillage equipment and encourage farmers to join various farmer organisations. Good rapport and trust with farmers is essential. Trainings on proper use of herbicides and potential harm of herbicides should be supported. Use of artificial incentives as empowerment packages can increase the adoption of CA. Effective feedback from farmers through monitoring and evaluation is essential. In the promotion of $\mathrm{CA}$, it is important to pay attention to both quantitative and qualitative factors.

\section{Acknowledgements}

I am deeply indebted to my supervisor Dr. Fred H. Johnsen and co-supervisors Dr. Jens B. Aune and Dr. Thomson H. Kalinda for their useful input on this paper. My special thanks go to Noragric $\mathrm{PhD}$ candidates peer review pressure group for their comments and I also give my sincere gratitude to the two anonymous reviewers for their suggestions.

\section{References}

Adesina, A. A., \& Zinnah, M. M. (1993). Technology characteristics, farmers' perceptions and adoption decisions: A Tobit model application in Sierra Leone. Agricultural Economics, 9, 297-311.

Agresti, A. (2007). An Introduction to Categorical Data Analysis (2 ed.). Hoboken, New Jersey: JohnWiley \& Sons, Inc. (Chapter 4). http://dx.doi.org/10.1002/0470114754

Aikens, M. T., Havens, A. E., Flinn, W. L. (1975). The adoption of innovations: the neglected role of institutional constraints, Mimeograph. Columbus, OH: Department of Rural Sociology, Ohio State University.

Bandura, A. (1969). Social-learning theory of identificatory processes. In D. A. Goslin (Ed.), Handbook of Socialization Theory and Research (pp. 213-262). Chicago: Rand McNally

Bandura, A. (1977). Social learning theory. London: Prentice-Hall International, (Chapters 1 and 2).

Carvalho, S., \& White, H. (1997). Combining the qualitative and quantitative approaches to poverty measurement and analysis: The practice and potential, World Bank technical paper no. 366. Washington, D.C: The World Bank.

CFU. (2006). Reversing Food Insecurity and Environmental Degradation in Zambia through Conservation Agriculture. Lusaka: Conservation Farming Unit.

CFU. (2009a). Conservation Farming \& Conservation Agriculture Handbook for Ox Farmers in Agro-Ecological Regions I \& II. Lusaka: Conservation Farming Unit, (Chapter E).

CFU. (2009b). Conservation Farming and Conservation Agriculture Hand Book for Hoe Farmers in Agro-Ecological Regions I \& IIa-Flat Culture. Lusaka: Conservation Farming Unit, (Chapter C).

CFU. (2011). The practice of Conventional and Conservation Agriculture in Eastern and Southern Africa. Lusaka: Conservation Farming Unit.

Chambers, R., \& Conway, G. (1991). Sustainable Rural Livelihoods: Practical Concepts for the 21st Century: Institute of Development Studies.

Chomba, G. N. (2004). Factors affecting smallholder farmers' adoption of soil and water conservation practices in Zambia, MSc Thesis: Michigan State University, (Chapter 3).

Creswell, J. W. (2009). Research design: quantitative, qualitative, and mixed methods approaches (3 ed.). London: Sage, (Chapters 1 and 10).

Curtis, A. L., \& De Lacy, T. (1996). Landcare in Australia: does it make a difference? Journal of Environmental Management, 46(2), 119-137. http://dx.doi.org/10.1006/jema.1996.0011

Derpsch, R., Friedrich, T., Kassam, A., \& Hongwen, L. (2010). Current status of adoption of no-till farming in the world and some of its main benefits. International Journal of Agricultural and Biological Engineering, 3(1), 1-25. http://dx.doi.org/10.3965/j.issn.1934-6344.2010.01.001-025

Dumanski, J., Peiretti, R., Benetis, J., McGarry, D., \& Pieri, C. (2006). The paradigm of conservation tillage. Proceedings of World Association of Soil and Water Conservation Paper presented at the World Association of Soil and Water Conservation, India, 58-64.

FAO. (2006). State of Food Insecurity. Rome: FAO.

FAO. (2011a). Climatic Risk Analysis in Conservation Agriculture in Varied Biophysical and Socio-economic Settings of Southern Africa, Network paper, 3. Rome: FAO. 
FAO. (2011b). Socio-Economic Analysis of Conservation Agriculture in Southern Africa, Network No. 2. Rome: FAO.

Friedrich, T., Derpsch, R., \& Kassam, A. (2011). Global Overview of the Spread of Conservation Agriculture. Paper presented at the 5th World Congress on Conservation Agriculture, Brisbane, 26-29 September

Giddens, A. (1984). The constitution of society: outline of the theory of structuration Cambridge, UK: Polity Press, (Chapter 1).

Giller, K. E., Witter, E., Corbeels, M., \& Tittonell, P. (2009). Conservation agriculture and smallholder farming in Africa: The heretics' view. Field Crops Research, 114(1), 23-34. http://dx.doi.org/doi:10.1016/j.fcr.2009.06.017

Govaerts, B., Verhulst, N., Castellanos-Navarrete, A., Sayre, K. D., Dixon, J., \& Dendooven, L. (2009). Conservation Agriculture and Soil Carbon Sequestration: Between Myth and Farmer Reality. Critical Reviews in Plant Science, 28, 97-122. http://dx.doi.org/10.1080/07352680902776358

Haggblade, S., \& Tembo, G. (2003a). Conservation Farming in Zambia, EPTD Discussion paper no.108: International Food Policy Research Institute.

Haggblade, S., \& Tembo, G. (2003b). Development, Diffusion and Impact of Conservation Farming in Zambia Working paper 8. Lusaka: Food Security Research Project.

Hobbs, P. R., Sayre, K., \& Gupta, R. (2008). The role of conservation agriculture in sustainable agriculture. Philosophical transactions of the royal society, 363, 543-555. http://dx.doi.org/10.1098/rstb.2007.2169

Johnson, R. B., \& Onwuegbuzie, A. J. (2004). Mixed Methods Research: A research paradigm whose time has come. Educational researcher, 33(7), 14-26. http://dx.doi.org/10.3102/0013189X033007014

Kabamba, H., \& Muimba-Kankolongo, A. (2009). Adoption and impact of conservation farming on crop productivity among smallholder farmers in Kapiri Mposhi District of Zambia. Journal of Animal and Plant Sciences, 3(2), 205-214.

Kabwe, G. (2010). Uptake of Agroforestry Technologies among Smallholder Farmers in Zambia, PhD Thesis: Lincoln University, (Chapter 3).

Kalinda, T., Bwalya, S., Mulolwa, A., \& Hantuba, H. (2008). Use of Integrated Land Use Assessment (ILUA) data for forest and agricultural policy review and analysis in Zambia. Lusaka: FAO \& MTENR.

Kassam, A., Friedrich, T., Shaxson, F., \& Pretty, J. (2009). The spread of Conservation Agriculture: justification, sustainability and uptake. International Journal of Agricultural Sustainability, 7(4), 292-320. http://dx.doi.org/10.3763/ijas.2009.0477

Knowler, D., \& Bradshaw, B. (2007). Farmers' adoption of conservation agriculture: A review and synthesis of recent research. Food Policy, 32(1), 25-48. http://dx.doi.org/doi:10.1016/j.foodpol.2006.01.003

Li, L., Huang, G., Zhang, R., Bill, B., Guangdi, L., \& Kwong, Y. C. (2011). Benefits of Conservation Agriculture on Soil and Water Conservation and Its Progress in China. Agricultural Sciences in China, 10(6), 850-859. http://dx.doi.org/10.1016/S1671-2927(11)60071-0

Long, N. (1992). From paradigm lost to paradigm regained? The case for an actor-oriented sociology of development. In N. Long \& A. Long (Eds.), Battlefields of Knowledge: The Interlocking of Theory and Practice in Social Research and Development (pp. 16-43). London: Routledge.

Marongwe, L. S., Kwazira, K., Jenrich, M., Thierfelder, C., Kassam, A., \& Friedrich, T. (2011). An African success: the case of conservation agriculture in Zimbabwe. International Journal of Agricultural Sustainability, 9(1), 153-161. http://dx.doi.org/10.3763/ijas.2010.0556

McGowan, C. (2011). Women in agriculture. In D. Pannell \& F. Vanclay (Eds.), Changing Land Management. Adoption of New Practices by Rural Landholders (pp. 141-152). Collingwood: CSIRO.

MINITAB. (2010). Advantages of Minitab's General Regression Tool.

Mwaseba, D. L., Kaarhus, R., Johnsen, F. H., Mvena, Z. S. K., \& Mattee, A. Z. (2006). Beyond adoption/rejection of agricultural innovations: Empirical evidence from smallholder rice farmers in Tanzania. Outlook on Agriculture, 35(4), 263-272. http://dx.doi.org/10.5367/000000006779398245

Newing, H. (2011). Conducting Research in Conservation. A Social Science Perspective. London: Routledge. 
Nyanga, P. H., Johnsen, F. H., \& Aune, J. B. (2011). The Conservation Agriculture Project (CAP) Implemented by the Conservation Agriculture Unit (CFU) of Zambia National Farmers Union (ZNFU) 2009/2010 Monitoring and Evaluation Report. Ås: Noragric.

Rogers, E. M. (2003). Diffusion of Innovations ( $5^{\text {th }}$ ed.). London: Free Press, (Chapter 1 and 5).

Siegel, B. P., \& Jeffrey, A. (2005). Poverty Reducing Potential of Smallholder Agriculture in Zambia: Opportunities and Constraints, Working paper Series No. 85. Washington, DC: World Bank.

Sobel, J., Curtis, A., \& Lockie, S. (2001). The role of Landcare group network in rural Australia: exploring the contributions of social capital. Journal of Rural Studies, 17(3), 167-178. http://dx.doi.org/110.1016/S0743-0167(1001)00003-00001

Twomlow, S., \& Hove, L. (2006). Is Conservation Agriculture an Option for Vulnerable Households?, Briefing Note No. 4. Bulawayo: International Crops Research Institute for the Semi-Arid Tropics.

Vanclay, F. (2011). Social principles for agricultural extension in facilitating the adoption of new practices. In D. Pannell \& F. Vanclay (Eds.), Changing Land Management. Adoption of New Practices by Rural Landholders (pp. 51-68). Collingwood: CSIRO. 